\title{
On the Practice of Developing Vision-centered Tasks for the Local Materials for Learning English: A Case of Iranian Secondary Schools English Language Coursebooks
}

\author{
Majid Elahi Shirvan \\ University of Bojnord, Iran; Email: elahimajid64@gmail.com \\ Negin Maddah \\ University of Bojnord, Iran; Email: maddahnegin@gmail.com
}

Doi:10.5901/mjss.2015.v6n6s4p340

\begin{abstract}
A large number of research studies have contributed to the significant role of motivation in the field of applied linguistics. Recently, based on the L2 motivational self model and the concept of ideal self, the concept of the desired second language learner vision have been introduced. However, the gap between the theories in applied linguistics and their practice in materials development is also seen in the practice of vision centered tasks for English language learners. With the publication of the new course books for learning English at Iranian secondary schools entitled PROSPECT the need for the adaptation of these local materials in light of the construction of the successful English language learners' vision is felt. Thus, the purpose of the present study was to develop vision-centered tasks for the first book of PROSPECT series. To do so, vision-centered tasks for all the units of the book related to their themes and topics were developed based on the framework of successful language learners' vision. First, tasks were developed to help learners create their own vision of successful learner. Next, created vision was followed by some tasks to strengthen it and make it plausible. Besides, some other tasks were developed to focus on the transfer of such visions into actions, keeping them alive as well as counterbalancing learners' vision by their failure. The results of the pilot of these tasks indicated the success of English language learners in the construction of successful language learners' vision.
\end{abstract}

Keywords: Motivation, vision-centered task, creating vision, sustaining vision, Prospect series.

\section{Introduction}

Lots of studies have paid attention to the importance of motivation in learning English as a second or foreign language. Besides, several models of motivation have been proposed based on different theories of motivation. Recently, Dornyie and Kubanyiova (2014), inspired by the ideal self image, maintained that one decisive way to improve the learners' level of motivation is to help them to have vision of their desired second language self as well as the ultimate goal of their learning process. However, one main issue encountered within the field of applied linguistics, as mentioned in Tomlinson (2013), is the gap between these theories and their practice in the field of materials development. The global and local materials for learning English are supposed to take advantage of these theories. Recently, new series of course books for learning English, PROSPECT, have been developed to be used at Iranian high schools. Developing tasks in light of the construction of successful English language learners' vision seems essential because Iranian high school learners using PROSPECT series are at their fledgling state of learning English; thus, the ability to create visions of successful English language learners can contribute to their achievement in the next stages of language learning. The aim of this study was to develop tasks based on the vision framework suggested by Dornyie and Kubanyiova (2014). These tasks provide English language learning materials, in this case PROSPECT 1, with the potential of motivating language learners to be engaged in the process of language learning.

\section{Review of Literature}

The gap between theories of applied linguistics and language teaching practice has turned into a big issue in applied linguistics (Tomlinson, 2013). This gap can be bridged by bringing together researchers, writers, and publishers in order to pool resources for some firm solutions (Tomlinson, 1998). A deeper look at the reasons underlying this gap can pave the way for better ways of the applications of the theories of applied linguistics in materials development. Some of these 
reasons might be due to the fact that materials for learning English are mainly "written in language which is not easily accessible to practitioners" (Tomlinson, 2013, p.2). Second, they rarely take into account the realities of the classroom such as the low level of learners' motivation, lack of adequate time, size of the classes, lack of resources, and the exam oriented atmosphere of the classes. Third, the innovations required in the application of the theories of applied linguistics in materials might seem unappealing to their users (Tomlinson, 2013).

In the same vein, Prowse (1998) reported that despite some cases of the practice of the theories of second language acquisition in materials development (e.g. McGrath2002, Bell and Gower2011, Jully and Bolitho2011), writers mainly write materials based on their inspiration and knowledge of theories as well as their experience "but none of them report developing principled criteria or framework before or while writing" (Tomlinson, 2013, p.2).

To set the stage for narrowing the gap between theories of second language acquisition and their practice in materials development, Tomlinson (2013) referred to different attributes that facilitate the process of second language acquisition. One of these attributes is preparing a condition to provide learners with adequate time, silence, and motivation to take advantage of their inner voices and by textbooks using a personal voice.

The importance of motivation in second language learning has been proved today. Dornyei and Kubanyiova (2014) have explained that the level of motivation is so decisive for learning and mastery of the second language that without it "appropriate curricula" and "good teaching" are not enough to ensure students achievement. They have also argued that motivation helps learners to take the responsibility of their own learning.

There has been a lot of research about the concept of second language learning motivation for over five decades. These studies are mainly divided into three broad phases: the social psychological period (1959-1990), the cognitivesituated period (during the 1990s) and new socio-dynamic approaches in the first decades of the twenty-first century.

The social psychological period is known by the work of social psychologist Robert Gardner and his associates in Canada (e.g. Gardner 1985; Gardner and Maclntyre 1993). Integrative orientation/motivation, the desire to learn a prestigious second language for communication, and instrumental orientation/motivation, benefits of second language learning in everyday life, are two well-known concepts of this period (Dornyie \& Kubanyiova, 2014).

The cognitive-situated period is developed by the studies related to contemporary cognitive theories from educational psychology. Two general objectives in this period are the desire to bring second language motivation theory and motivational psychology in the same line and the adaptation of a more situated analysis of motivation in specific learning settings. Extrinsic and intrinsic motivation that is the performance of a behavior as a means to an end, attributes like the way a person face with his/her past success or failure and self confidencelefficacy or situation-specific motives are important concepts stemming from cognitive-situated period (Dornyei \& Kubanyiova, 2014).

The third period is the new socio-dynamic approaches. The decisive characteristic of this period is the interest in motivational change and "the relationship between motivation and identity in specific social contexts". The processoriented conceptualization of motivation, motivation as investment and a dynamic systems perspective in motivation are concepts stemming from this period (Dornyei \& Kubanyiova, 2014).

Dornyei (2005), influenced by theories of second language motivation (e.g. Gardner 2001; Noels 2003; Norton 2001; Ushioda 2001), introduced second language motivational self system. This model consists of three main constituents: ideal second language self, ought-to second language self and second language learning experience (Dornyei, 2005).

The ideal second language self is the situation learner wants to achieve by learning a second language. Ideal second language self motivate students to learn to get closer to the ideal self (Dornyei, 2005). Ought-to second language self is defined as the features that a person should have or achieve to survive in a society that most of the time it is not similar to person`s own desires or wishes (Dornyei, 2005). The second language learning experience is more concerned with the effect of "learning environment and experience" on learners (Dornyei, 2005). In this model the first two concepts are related to the future self and the third one is concerned with the actual self. Inspired by this model, Dornyei and Kubanyiova (2014) directed the concept of motivation to the concept of successful vision of English language learners.

According to the Oxford English Dictionary, a vision is 'the ability to think about or plan the future with imagination' or 'a vivid mental image, especially a fanciful one of the future' (Dornyei and Kubanyiova, 2014, p.9).

Dornyei and Kubanyiova (2014) explained that constructing the learners' vision of their desired future second language self is the first step in a motivational intervention program. So in developing vision-centered tasks the first step is to help learners to create their own vision, "who they would become as second language users and what knowing a second language could add to their lives" (Dornyie \& Kubanyiova, 2014, P.34) They asserted that creating successful vision in students and teachers should follow some rules as: "understanding students" current identity concerns and lived experiences", " providing regular tasters of desired future states", "applying guided imagery", "applying guided narratives" and "ensuring ample exposure to role models". 
After the creation of vision in second language learners the next step is "strengthening the vision through imagery enhancement" (Dornyei \& Kubanyiova, 2014, p.65) under four key principles, namely, relaxation, realism, regularity, and reinforcement. They (2014) also explained that imagery workout "help learners to be more sensually aware of the environment_the principle of 'practice makes perfect' also applies to imagery skills". Also using practices like video selfmodeling is suggested in this part (Dornyei \& Kubanyiova, 2014). Dornyei and Kubanyiova (2014) referred to some other ways of strengthening the created vision such as "building creative visual and narrative tasks into the teaching routine" by using tasks like "image portfolio, vision journal, creative visual survey, telling your future story creatively and embroidering the learners' 'back to the future' language learning history" (P.72). In addition, the technique of "transporting students into the narrative world of their future vision" can strengthen the vision created by learners through extensive readings for second/foreign language learners. Other strategies to strengthen students' vision are: "encouraging students to keep learning journals", "harnessing the power of virtual worlds through avatars and virtual environments and online gaming spaces" and "strengthening the whole groups' vision" (P.78-82) Furthermore, an effective way of strengthening the learners' individual vision is generating the collective vision of the whole group the learners belong to seems to be an effective way of strengthening the individuals' vision. Some of these strategies consist of "pooling individual narratives", "modeling group vision through transformational leadership" and "communicating the vision effectively" (Dornyei \& Kubanyiova, 2014, p.84).

The third step is "substantiating the vision by making it plausible". In other words, students should have positive feelings towards their vision and when they feel they can do something, they try to do it completely to fulfill the gap between their desired self and their current situation (Dornyei \& Kubanyiova, 2014). Plausibility of the strengthened vision can take place under three assumptions: "cultivating realistic beliefs about language learning", "creating channels for constructive reality self-checks" and "eliminating obstacles and barriers" (Dornyei \& Kubanyiova, 2014, p.90-97).

Transforming the vision into action is the next step or the operationalisation of the vision. First, separated ambitions subsumed by the vision should be identified and applied as the basis for a set of long-term goals. These, then, need to be further broken down into specific short-term goals which are actionable. This narrowing process should eventually result in specifying concrete language tasks and accompanying task-execution strategies. There are three approaches to transform the vision into action: "providing students with models of self-relevant roadmaps", "mapping out pathways to success through visualization" and "providing students with individual guidance" (Dornyei \& Kubanyiova, 2014, P.101105).

The fifth step in developing vision-centered tasks is "keeping the vision alive". There are different aspects of our life that have several related and distinct possible selves. Besides, we have different self-images related to our desires and selves. So, we cannot have all these images active in our working memory at the same time. In order to keep our vision among other things in our working memory alive, we should activate it regularly. There are three approaches to help learners to keep their vision alive such as "including regular reminders and 'priming stimuli' in the teaching content", "engaging learners' transportable identities" and "helping to re-envisage 'broken' visions" ( Dornyei \& Kubanyiova, 2014, p.107).

The last step in explaining the framework of vision-centered tasks is "counterbalancing the vision by considering failure. It means that the vision of the ideal self should be balanced against a consideration of what would happen if the desired self were not realized". Three approaches to counterbalance the vision are: "offering regular reminders of the negative consequences of not succeeding", "foregrounding the ought-to self" and "integrating images of feared selves into visualization" (Dornyei \& Kubanyiova, 2014, P.115).

It is worth mentioning that the principles of the framework above are not be used as a linear process to improve learners vision. After creating the vision in learners, other principles and steps can be used even at the same time in tasks and by teachers (Dornyei \& Kubanyiova, 2014).

Considering this framework, the researchers in this study found the gap of the practice of the construction of successful language learners' vision in the course books for learning English. This vision seems necessary especially at the early stages of language learning because the construction of a successful vision can sustain the efforts language learners make and guarantee their achievement. Thus, the development of tasks and materials for this purpose can lay the foundation of the successful process of language learning. PROSPECT 1, the official book of learning English at the elementary level in Iran, can foster this prospect, the successful vision, provided that tasks for this purpose are developed. Therefore, the purpose of this study was to practice the construction of language learners' vision orientation in PROSPECT 1 via the development of tasks based on the framework introduced above as well as bridging the gap between one main proposed theory in applied linguistics on one hand and materials development on the other hand. 


\section{Method}

\subsection{Participants}

15 English language learners from five high schools of Bojnord, Iran, participated in the interviews. Their age ranged from 11 to 13 and two of them did not report their age. Their first languages were mainly Persian, Kurdish, and Turkish. All of them had no background of learning English before.

\subsection{Materials}

Recently, new course books were published in Iranian schools entitled PROSPECT. The first book of this series, English for schools, is PROSPECT 1 which includes a student book, a work book, teacher's guide, CD and flash cards for teacher. PROSPECT 1 consists of eight lessons and each two lessons is accompanied by a review part. Each lesson covers teaching sounds of English and sections regarding conversation, practices, practices for listening and photo dictionaries for teaching new vocabularies at the end of the book.

\subsection{Criteria for materials development}

Since PROSPECT 1 is officially the first English book for Iranian students in schools, motivating students to learn English is so decisive for their future learning. One way of motivating learners is to help them to create their desired second language self. Based on the model proposed by Dornyei and Kubanyiova (2014), in this study the tasks were developed according to the framework to create and strengthen the vision, make it plausible, transform it into action, keep it alive, and counterbalance it in language learners. You can see the framework in the table 1, below.

Table 1. Framework for developing vision-centered tasks

\begin{tabular}{|c|c|}
\hline Motivational conditions for desired future language selves & $\begin{array}{l}\text { Key facets of a vision-centered motivational } \\
\text { practice }\end{array}$ \\
\hline $\begin{array}{l}\text { The learner has a desired future self-image (vision) which is related to but is } \\
\text { also different from his/her current self-concept. } \\
\text { The vision is elaborate and vivid. } \\
\text { The vision is perceived as plausible but not comfortably certain, and it does not } \\
\text { clash with other parts of the individual's self-concept, particularly with the } \\
\text { expectations of the learner's family and peers. } \\
\text { The vision is accompanied by relevant and effective procedural strategies that } \\
\text { act as a roadmap towards the goal. } \\
\text { The vision is regularly activated in the learner's working self-concept. } \\
\text { The learner is also aware of elaborate information about the negative } \\
\text { consequences of not achieving the desired end state. }\end{array}$ & $\begin{array}{l}\text { Creating the language learners' vision } \\
\text { Strengthening the vision through imagery } \\
\text { enhancement } \\
\text { Substantiating the vision by making it plausible } \\
\text { Transforming the vision into action } \\
\text { Keeping the vision alive } \\
\text { Counterbalancing the vision by considering failure }\end{array}$ \\
\hline
\end{tabular}

Derived from Motivating Learners, Motivating Teachers (Dornyei \& Kubanyiova, p.32)

\subsection{Interview}

Semi-structured interviews based on the six stages of the framework were conducted with 15 interviewees. Semi structured interview was conducted because this kind of interview is suggested for cases that researchers are almost professional in one specific domain and therefore they have the ability to provide interviewees with overall questions in that specific domain. Besides, they do not want to narrow the responses of the interviewees by using 'ready-made response categories'. To do this researchers use 'interview guide'. They ask the same questions from all the interviewees but the order and wording of the questions can be different (Dornyei, 2007). Since the students' perspectives toward tasks were significant to evaluate their effectiveness, applying semi-structured interviews to be aware of their perspectives was considered suitable for this study. The structured nature of interview provided the interviewers with the prepared questions and, as the part -semi suggests, allowed the interviewees to answer the questions in a way they felt encouraged (Dornyei, 2007). 


\subsection{Procedure of task development}

The sample tasks were developed based on the five stages of the framework. The tasks developed might cover one or more stages of the framework at the same time. Some of them were specifically related to the themes of the lessons of PROSPECT 1 but some of them mainly focused on the stages of the framework per se like the creation and the plausibility of the visions. The significance and the interpretations of the developed tasks were reported with regard to their underlying aspects and stages of the framework. In general, three of four tasks for each lesson on PROSPECT 1 were developed. Next, they were piloted in two high schools of Bojnord to make sure the content, purpose, and organization of each task were clear for the learners. Then, they were practiced in five high schools of Bojnord, Northern Khorasan. Due to the time limitation and the strict policies of the schools, the researchers practiced the vision developed tasks for each two units of PROSPECT 1 in different high schools. For example, the tasks for units 1 and 2 were practiced in one high school and the tasks for units 6 and 7 were practiced in another high school. At the end of each session, semi-structured interviews were conducted with 3 learners of each class who were volunteer to participate for the interview. Each interview took about 10 minutes and their responses were recorded and then transcribed. They were then analyzed and coded based on the main aspects of the framework for the construction of successful language learners' image.

In the process of conducting the interviews, first the researchers had the ice-breaking period. The first few questions were developed in a way making a good rapport between the interviewer and the interviewee. To achieve this, the researchers started the interview with some personal questions like the interviewees' family, etc. This was to help the interviewees to feel at ease. Then they were asked to cover different aspects of the topic. During the interview rich and more detailed responses by using the six stages of the vision framework as the interview guide were elicited. Finally, each interview was ended up with some final closing questions, especially some simple ones. For example, the interviewees were asked to add something if they would like to. To conduct the interviews and to focus more on the responses, the researchers recorded them meticulously. It is worth mentioning that the interviewees were aware of the process of recording.

\section{Examples of Adaptation of Activities for the Development of Vision for PROSPECT1}

\subsection{Example 1}

The following example can be included in the first lesson of PROSPECT 1 as it is the preliminary for the construction of the vision in language learners. The purpose of the task is to create the language learners' vision. Particularly in this task, it is aimed to find out more about the students. The title of this activity is your language learning life history and students need to find out the relation of their experiences when they start to learn English with their current situation. They are also become aware of the things that help them develop their ability in English (Dornyei \& Kubanyiova, 2014). In this activity they imagine that they are in the future with high ability in English and now they want to write their experiences. As students in this have a low level of English, the task can be answered in Persian.

Language Learning Life History

1. Write your language learning life history in Persian and answer the following questions in your writing.

a. Why did you learn English?

b. How do you feel now?

c. What are the effects of learning English for you?

\subsection{Example 2}

The purpose of the following example is to strengthen the created vision by training imagery skills. Imagery training is beneficial for educational purposes. It helps learners to be ready for real situations. The aim of this activity is to counterbalance the vision by considering the failure. In this way students imagine a situation in which they are not able to communicate in the target language and describe their feelings. Thus, they might be encouraged to learn the language to fill the gap between their current situation self and their desired second language self. The following is the example from lesson two in PROSPECT 1. The topic of this lesson is introducing a classmate to others.

Close your eyes and do some deep slow breathing, imagine yourself in one of the European countries e.g. England, you have to live there for a while because of your father's job. So you have to study in schools with English teachers and students. All of your classmates are native speakers of English except you and your Iranian friend. It is the 
first day of school and you want to introduce your Iranian friend to them. Can you do this? Describe your feelings. Imagine you fail to do it. Describe your feelings.

\subsection{Example 3}

The following task can be included in lesson three in PROSPECT 1. As you see the topic of the reading is related to the topic of the lesson, Birthday and Dates. The purpose of the activity is to strengthen the vision in language learners by using imagery training. Asking students to imagine themselves in Mika's situation, which was derived from Select Reading and also in London among English speaking students, is helpful to improve learners' sense of imagination and self confidence. This way learners' performance will be better due to this engagement. Also the use of reading comprehension in this part helps students to be transported into the narrative world of their future vision. Since there are not any reading comprehension activities in PROSPCT 1, this kind of activity strengthens the learners' successful vision via their engagement in a reading comprehension activity. In addition, this task can contribute to the plausibility of the vision for language learners by cultivating realistic beliefs about language learning. Asking students to search about people in other countries and living abroad can help them to have a dream not only possible but also plausible. Dreams that are just based on unrealistic positive or negative beliefs will have negative influence on learners' motivation. Since unrealistic dreams will fail one day and destroy learners' vision (Dornyei \& Kubanyiova, 2014).

Read the following passage and answer the questions.

Mika's Homestay in London

By Mika Tanaka

Mika Tanaka, a college student from Japan, had a wonderful home stay in Landon. She lived with a British family and studied English for a month.

"What do you want for your I9th birthday?" my parents asked me.

"A ring," I replied. However, instead of a ring, my parents gave me a one-month home stay in London.

On February 11, I left Japan. On the plane, I worried about being all alone there - a stranger to London. But when I met the Flannery family (my host family), their warm welcomes made me feel at ease. Both my host father and mother were very kind and treated me like their own daughter.

Getting Ready to Go

Before going to London, I did some research on English schools in London and chose Oxford House College, mainly because it had reasonable fees. Also, there weren't many Japanese students at Oxford House.

I took my parents' advice and requested that my home stay family have both a mother and a father, be native-born, non-smoking, middle-class British people, and live near a subway station. I later found that this was very good advice, since some of my friends at the English school were having problems with their host families.

Living in London

Potatoes! It took me a little time to get used to the many kinds of potato dishes served: fried potatoes, steamed potatoes, sliced potatoes, and different-colored potatoes. My host mother was a good cook. She made delicious pasta and chicken dishes and even cooked rice for me.

Nadiege, a French girl, was another home stay student living with us, and we went around London together. On Saturdays, my host family would have a party at home with friends or family. When we returned from touring London, Nadiege and I would join the party. On Saturday evenings, Mr. and Mrs. Flannery would go to their favorite pub to spend time together.

Although I selected a school with few Japanese students, there were still at least two in each class. In class, I tried to speak a lot, but many Japanese students didn't use their English very much (even if they had Large vocabularies), and spoke only Japanese with their friends.

Sometimes, I asked other people their impressions of Japan. 'Japanese people work too hard,' said my French friend. My teacher thought that Japanese people were very rich. I did not agree with theses points, but I was interested in knowing what foreign people thought. One month in London made me realize that speaking English was very important, because it is the language that people from many countries use the most. I would like to be more open-minded about people from different countries, like my host family is.

Derived from Select Reading, (chapter2), P 11

Questions:

1. What was the Mika`s birthday present? Do you like such a gift for your birthday?!

2. Imagine you have a gift like that of Mika, search about studying abroad, e.g. people`s culture in London, their attitude toward Iranians, and your course of study there. 
3. Imagine yourself in London, it is the first day of school, the teacher asks the date. Can you answer him/her?! Do you know the months in English? Do you know how to say the date in English?

4. What is your idea about people in other countries? Why do you want to learn English?

\subsection{Example 4}

The following activity is developed for lesson four of PROSPECT 1. By doing this task students will be provided with models of appropriate roadmaps to attaining their second language selves. They can visualize their pathways to perform better. Furthermore, by asking students about their obstacles and their reasons to learn English, they will be aware of their barriers and try to find ways to eliminate them. This helps the learners to make their vision more plausible.

Perform a dialogue, in which you are talking to your future second language self. Ask yourself about obstacles on your way to learn English. Were your parent's ideas about learning English obstacles? Was there any reason that forced you to learn English? For example your face in society! List your reasons and also the strategies you used to learn English.

\subsection{Example 5}

This activity is Making Strategy Board. Making strategy board is useful for learners to articulate and being aware of different ways to fill the gap between their current self and their desired situation. For this, students make a poster board and use colored stickers to map out their next year or even their adult possible selves (Dornyei \& Kubanyiova, 2014). This kind of activity is used to transform the vision into action by mapping out pathways to success through visualization. In this way learners visualize the pathway and the process it to obtain their goals. In other words, they involve themselves in how they can achieve their desired second language self (Dornyei \& Kubanyiova, 2014). Another feature of this task is to re-envisage 'broken' visions that help them to keep it alive. 'Broken' visions are those visions which may be outdated, seem impossible or wrong after a while. In other words, they encompass the imaginary world of learners (Dornyei \& Kubanyiova, 2014). The following example is developed for lesson five in PROSPECT 1. The topic is of this lesson is My Appearance.

In lesson one you create your vision board of your second language ideal self. Now, review your vision board. Reenvisage your wrong or impossible vision and change your vision board where necessary. On your vision board write the strategies to get your ideal second language self. Link the strategies with lines to the future identities that you are expected to lead to. This is your strategy board.

\subsection{Example 6}

In the last example in this part, on one hand imagery training is used to strengthen the vision and on the other hand we counterbalance the vision by considering failure. "Integrating images of feared selves into visualization" (p. 118) is highlighted in this task. In this way learners face the feared self and in order to avoid this feeling in reality they try to master the language effectively. The following example is developed for lesson eight in PROSPECT 1. The topic of lesson eight is My favorite food.

6. A) Imagine you are in Mashhad. You are in a restaurant. You see a tourist. She wants to order "sholeh" but does not know what it is. She asks you about the ingredients, you know the ingredients in Persian but can you explain the ingredients of "Sholeh" in English?

B) How would you feel if you were not able to explain the ingredients in English? Describe your feelings

\section{Results}

The following table shows the percentage and frequency of the participants' responses in the six stages of the framework.

Table 2: The frequency and percentage of the participants' responses in each stage of the framework

\begin{tabular}{|l|c|c|}
\hline Stage & Frequency & Percentage \\
\hline Creating the language learners' vision & 12 & 80 \\
\hline Strengthening the vision through imagery enhancement & 13 & 86 \\
\hline Substantiating the vision by making it plausible & 14 & 93 \\
\hline
\end{tabular}




\begin{tabular}{|l|l|l|}
\hline Transforming the vision into action & 11 & 73 \\
\hline Keeping the vision alive & 13 & 86 \\
\hline Counterbalancing the vision by considering failure & 11 & 73 \\
\hline Total number of students & 15 & \\
\hline
\end{tabular}

As indicated in table 2, most of the participants, having high percentages and frequencies, were successful in the six stages of the framework. In the interviews, the majority of the interviewees maintained that doing the tasks developed for the construction of their visions as successful English language learners had the positive influence in motivating them for learning English.

Twelve of fifteen interviewees asserted that doing the task entitled language learning life history had improved their motivation by helping them to create the vision of their desired second language self. One of them said:

Doing this task made me think how important it is to create my future vision of learning English. So I feel more interested in learning English than before to narrow the gap between my current knowledge and my desired vision of English language learner.

Another one said:

When I thought about my future and the role of English in it, I feel more interested in learning English. By learning English I can improve my job, my communications, etc. So it has a positive influence in my whole life.

During the interview, most of the students were agreed that carrying out the task Introducing your friend in English... had positive impact on their created vision and helped them to strengthen it by imagery training. For example one said:

At first, seeing myself in London among English speaking students was so hard for me. But after a while I started to enjoy this vision. So I decided to introduce my friend to them. My failure made me upset! I felt embarrassed. I was afraid of being on that situation again. So I decided to make more efforts in learning English to avoid being in such embarrassing situations anymore!

Another one said: "Imagining myself in another country with the ability to speak English made me happy and excited to learn English. I think now it is possible to be a successful learner." "Now I have a vivid picture of myself while speaking English. This motivates me!" said another one of the participants.

In addition, regarding the plausibility of the constructed visions, some of the interviewees reported that by reading the passage entitled Mika's birthday present they felt closer to their desired vision and found it more tangible. For example one said:

While I was reading the text, I imagined myself in Mika's situation. I feel closer to my desired image of learning English. I think learning English will be easier if I have more information about the people who are in need of using English in their communication with people from different cultural backgrounds.

Another one said: "By doing this task I have a clearer image of having communication with native speakers in their countries and this picture helped me take learning English more serious than before".

Besides, the feedbacks of students indicated that doing the task performing a dialogue had a positive effect in knowing their obstacles and transforming their vision into action. One said: "Doing this task helped me to be aware of the problems in my way to turn my created vision into reality." Another one said:

Before doing this task, despite the successful image created, I was so uncertain about managing to achieve this vision because of the difficulties in the way. But now I can perform with more self-confidence to eliminate the barriers and make my desired vision of English language learner alive.

Furthermore, most of the interviewees expressed that making a strategy board contributed to their creation of a vivid pathway to accomplish their goals in learning English. Thus, reviewing their vision to improve or revise it seems useful to keep their vision alive. For example one said: "Making a strategy board had two advantages for me: it helped me to be aware of the practical strategies to turn my vision into reality while having fun! It can be like an interesting game!" "By reviewing my vision in strategy board I feel fresh to continue to work for my dreams!" said another one.

Finally, the interpretation of the ideas of the interviewees about the task, explaining the ingredients of the food in English, showed that almost the majority of the students were motivated to learn English to avoid situations that make them feel failure or fear. One of them said: "I felt really embarrassed when I couldn't answer the question of that tourist about the ingredients of Sholeh. I should try more to learn English." Another one said "If I couldn't communicate with that 
tourist in my own country, I would feel alone and desperate. I should consider more time to learn English from now on". Another one said "Learning English is really useful! I would like to communicate with foreigners in Iran and outside Iran and failure in this communication is really awful. I aim improve my English as soon as possible.

\section{Discussion}

The findings of the interview indicated that the practice of developing materials with activities around the construction of successful visions within the process of English language learning can lead to more conspicuous images in terms of the six stages of the framework. These findings can be interpreted from two main perspectives: first, Matthew effect, and second, Peter effect.

From the perspective of "Mathew effect", a biblical analogy first used by Merton (1968) explaining the sociological phenomenon of the poor get poorer while the wealthier get wealthier. In the field of applied linguistics, this analogy was used by Stanovich (1986) to explain children's reading development in light of Mathew effect. Being exposed to rich input of vocabulary and schemata, children will be more motivated to read and, as a result, learn more vocabulary and gain more background knowledge. This analogy can also be used in the practice of materials catering for the language learners' visions of successful language leaning. The more language learners are exposed to the types of activities and tasks aimed for the construction of successful English language learner, the more they can progress in the stages of the successful vision framework. Developing materials based on the framework of successful vision can provide Iranian secondary school English language learners with rich input in terms the main principles of the framework so that they enrich and activate the practice of vision construction among themselves. Creating their ideal image of an English language learner, being the hero of their narratives, actualizing this vision by making it more plausible than before and considering the cases of failure in the practice of this image can mainly be possible if they are practiced by the activities and materials developed for this purpose.

From the perspective of "Peter effect" which was coined by Applegate and Applegate (2004), a biblical analogy can offer clues about the possible changes and differences the practice of vision oriented materials can make in English language learners' process of learning. When asked for money by a beggar, Peter replied that he could not share what he did not have. Applegate and Applegate (2004) used this analogy to compare Peter with the teachers who are not interested in reading themselves and therefore cannot provide their learners with what "they do not have". The same analogy can be applied to what materials developed for learning languages "have" in terms of the main theories and findings achieved in applied linguistics. Thus, looking at the practice of vision construction from this perspective, if there are few materials for the construction of successful visions of English language learning, there will be few successful English language learners. A reflection on the ecosystem of human development and language learning ( van Lier, 2004, Bronfenbrenner \& Bronfenbrenner, 2009) can make us aware of the significant role of different environmental factors influencing the process of language learning such as teachers' interactions with learners, the learners' perceptions in language learning, classroom structure, teachers' behaviors; however, the role of materials, tasks, and activities within the complexity of this ecological perspective seems neglected. In other words, the practice of the construction of successful vision might be possible with the modifications made in the structure of the classrooms, teachers' attitudes, and the learners' orientations but the integrated network of these influential factors can be more effective if pivoted on the materials developed for the purpose of the construction of the successful images in learners. As shown in this study, the tasks which the learners faced could push them forward in terms of the vision they created, strengthened and made alive. Thus, secondary school Iranian English language learners can activate the vision of successful learners by carrying out the activities in the shape of materials developed in this study.

\section{Conclusion}

The match between theories proposed in second language acquisition research and their practice in materials developments has been a controversial issue in the field of applied linguistics. Thus, efforts are needed to bed made to narrow the gap between the two realms. Therefore, this study was conducted with the purpose of practicing the recent research framework of vision construction in the materials developed for secondary school English language learners in Iran. The findings regarding the success of these visions in terms of the stages of the framework represented in the interviews showed that the practice of these activities can contribute the motivation of these participants and; consequently, set the stage in their achievement in the process of English language learning. Since these students are at their fledgling stage of English language learning, the construction of successful vision can facilitate their actualization of their visions despite some constraints mentioned by their teachers such as time limitation and the need for more training 
courses to tailor their teaching behavior to the needs of their students using the new published books, PROSPECT series.

\section{References}

Applegate, A. J., \& Applegate, M. D. (2004). The Peter Effect: Reading habits and attitudes of preservice teachers. The Reading Teacher, 554-563.

Bell, J. Gower, R (2011). Writing Course Materials for the World: a great compromise. In B. Tomlinson (Ed.), Materials Development in Language Teaching. Cambridge: Cambridge university press.

Bronfenbrenner, U, \& Bronfenbrenner, U. (2009). The ecology of human development: Experiments by nature and design. Harvard university press.

Dornyei, Z. (2005). The Psychology of Language Learner. Mahwah, NJ: Lawrence Erlbaum.

Dornyei, Z. Kubanyiova., M. (2014). Motivating Learners, Motivating Teachers. Cambridge: Cambridge university press.

Dörnyei, Z. (2007). Research methods in applied linguistics: Quantitative, qualitative, and mixed methodologies. Oxford: Oxford University Press.

Gardner, R. C. (1985). Social Psychology and Second Language Learning. London: Edward Arnold.

Gardner, R. C. (2001). Integrative Motivation and Second Language Acquisition. In Z. Dornyei \& R. Schmidt (Eds.), motivation and second language acquisition (pp. 1-20). Honolulu HI: University of Hawaii press.

Gardner, R. C, \& Maclntyre, P. D. (1993). On the Measurement of Affective Variables in Second Language Learning. Language learning, 43(2), 157-194.

Jully, D. Bolitho, R. (2011). A framework for materials writing. In B. Tomlinson (Ed.), materials development in language teaching. Cambridge: Cambridge university press.

Mertonon, R. K. (1968). The Matthew Effect in Science. Science, 159(3810), 56-63.

McGrath, I. (2002). Materials evaluation and design for language teaching. Edinburgh: Edinburgh University Press.

Noels, K. A. (2003). Learning Spanish as a second language. In Z. Dornyei (Ed.), attitudes, orientations, and motivations in language learning (pp. 97-136). Oxford: Blackwell.

Norton, B. (2001). Non-participation, imagined communities and the language classroom. In M. P. Breen (Ed.), Learner contributions to language learning: new directions in research (pp. 71-159). Harlow: Longman.

Prowse, P. (1998). How writers write: testimony from authors. In B. Tomlinson (Ed.), Materials Development in Language Teaching. London: Cambridge university press.

Stanovich, K. E. (1986). Matthew effects in reading: Some consequences of individual differences in the acquisition of literacy. Reading research quarterly, 360-407.

Tomlinson, B. (1998). Materials Development in Language Learning. Cambridge: Cambridge university press.

Tomlinson, B. (2013). Applied linguistics and materials development. India: Bloomsbury.

Ushioda, E. (2001). Language learning at university. In S. R. Dornyei Z (Ed.), motivation and second language acquisition (pp. 19-34). Honolulu, HI: University of Hawaii Press.

Van Lier, L. (Ed.). (2004). the ecology and semiotics of language learning: A Sociocultural perspective (Vol. 3). Springer Science \& Business Media. 